\title{
The International Effects of Government Spending Composition
}

Giovanni Ganelli 


\title{
IMF Working Paper
}

Fiscal Affairs Department

\section{The International Effects of Government Spending Composition}

\author{
Prepared by Giovanni Ganelli ${ }^{1}$ \\ Authorized for distribution by Manmohan S. Kumar
}

January 2005

\begin{abstract}
This Working Paper should not be reported as representing the views of the IMF. The views expressed in this Working Paper are those of the author(s) and do not necessarily represent those of the IMF or IMF policy. Working Papers describe research in progress by the author(s) and are published to elicit comments and to further debate.

This paper helps resolve a paradox in the literature, noticed by Alesina and Perotti (1995), which is that, although government employment is an important component of public spending, the debate on the effects of fiscal policy focuses almost exclusively on shocks to non-wage government consumption. We incorporate the distinction between spending for government employment and spending for non-wage government consumption in a "new open economy macroeconomics" model. Our results show that a permanent reduction in public employment in one country reduces relative private consumption and appreciates the domestic exchange rate if it is matched by a reduction in taxes. When the reduction in public employment is used to finance increased non-wage government consumption, the macroeconomic effects results are ambiguous, and are affected by the initial level of the public wage bill.
\end{abstract}

JEL Classification Numbers: E620, F410

Keywords: Public spending composition, fiscal policy, open economy

Author(s) E-Mail Address: gganelli@imf.org

\footnotetext{
${ }^{1}$ I would like to thank Philip Lane for his useful comments.
} 


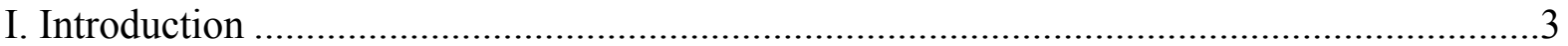

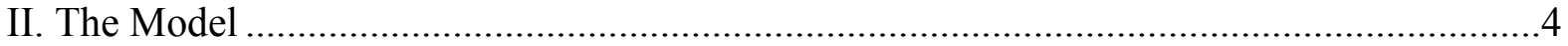

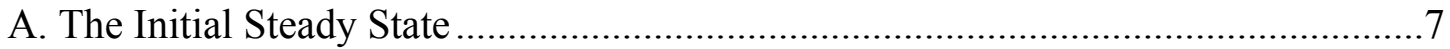

B. Short-Run Nominal Rigidities.........................................................................

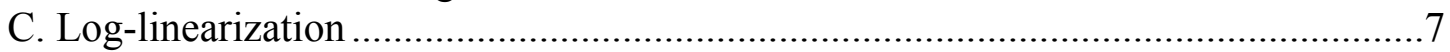

III. The Effects of Government Spending Composition .................................................8

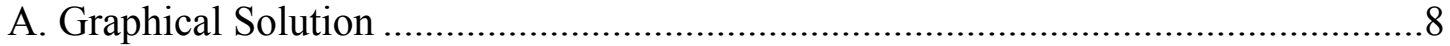

B. Effects of a Reduction in Government Employment ..........................................12

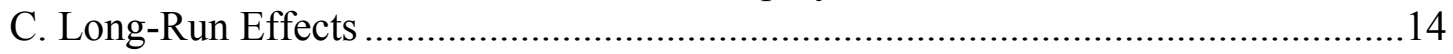

D. Effects of a Shift in Government Spending Composition......................................16

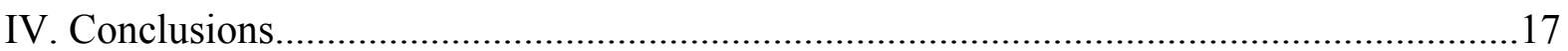

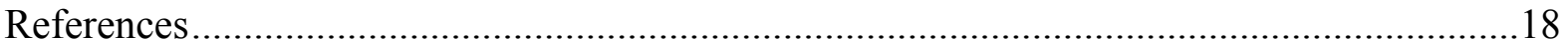

Tables

1. The Log-linearized Domestic Economy ..............................................................

Figures

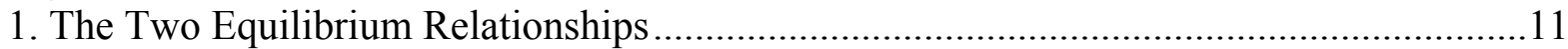

2. Effects of a Reduction in Domestic Government Employment....................................... 12 


\section{INTRODUCTION}

Both in ad hoc and in general equilibrium macroeconomic models government spending is generally introduced, explicitly or implicitly, only as non-wage government consumption of goods and services. ${ }^{2}$ As Alesina and Perotti (1995) notice, however, spending for public employment is an important component of government spending, while spending for non-wage public consumption tends to show the least significant dynamics, yet "paradoxically, government [non wage] consumption typically receives the most attention in the academic debate on the macroeconomic effects of fiscal policy" (Alesina and Perotti, 1995, p. 224). ${ }^{3}$ In this paper we help resolve this paradox of the literature, by analyzing the effects of government spending composition in a two-country general equilibrium sticky-price model.

Finn (1998) has incorporated the distinction between spending for public employment and for non-wage public consumption in a closed economy, flexible-price Real Business Cycle (RBC) model. In that context, she showed how failing to pay attention to such a distinction can lead to overestimation of the government's impact on the economy cycle. Our analysis differs from Finn's on a number of points (discussed in more detail in Section III(C)). Most notably, we use a two-country model belonging to the so-called "new open economy macroeconomics" strand of the literature rather than a RBC approach (see Obstfeld and Rogoff, 1995, 1996; and Lane, 2001). This allows us to study the impact of changes in the composition of public spending, not only on the long-run full-employment equilibrium, but also on the short run, in which output is demand-determined due to the presence of nominal rigidities. Furthermore, the open economy dimension allows an analysis of the effects of public spending composition on variables, such as the exchange rate and the current account.

Lane and Perotti (2003) show in an open-economy reduced-form model how the composition of public spending interacts with the exchange rate regime and has an empirical effect on macroeconomic outcomes. Since the "new open economy macroeconomics" is rapidly emerging as a new paradigm for the analysis of macroeconomic interdependence, our contribution also aims to provide further insights on the role of fiscal policy in this new framework, in addition to those that can be derived from ad hoc models (Lane and Ganelli, 2003, p. 329, stress the importance of moving the research agenda in this direction).

Our analysis shows that a permanent reduction in domestic government employment that is used to finance a reduction in general taxation implies an immediate increase in domestic private consumption compared to foreign. This result is mainly due to the fact that agents anticipate that they will have a lower lifetime tax burden, including in the new long-run equilibrium when the reduction in public sector employment will be compensated by increased employment in the private sector. Furthermore, under our assumptions, the sectoral shift in employment implies a

\footnotetext{
${ }^{2}$ Two noteworthy exceptions are Finn (1998), and Lane and Perotti (2003), which are discussed below.

${ }^{3}$ Italics added by author.
} 
more productive use of domestic resources, therefore easing current account pressures and allowing a more appreciated short-run exchange rate.

When the reduction in public employment is used to finance an increase in government nonwage consumption, the macroeconomic effects are ambiguous since in that case domestic agents do not gain from the reduction in the tax burden, but they benefit from the expansion in demand implied by higher public consumption. Our analytical results show that, following such policy, a stronger pressure for reduction in domestic relative private consumption emerges in cases in which the initial share of private income derived from employment in the public sector is larger.

The paper is organized as follows: the next section introduces the model, Section III discusses the effects of two macroeconomic policies with the help of a simple graphical apparatus; and Section IV concludes.

\section{THE MODEL}

There are two countries in the world, which we label Home and Foreign. The world is populated by a continuum of infinitely-lived agents. Total world population is normalized to 1 . Home agents are on the interval $[0, n]$, while foreign agents are on the interval $[n, 1]$. A measure 1 of firms also exist in the world. Each firm has some monopolistic power in the production of a differentiated good and $n$ firms are based in the domestic country while 1- $n$ firms are based in the foreign country.

Agents derive utility from consumption of a composite good, leisure and real balances. ${ }^{4}$ Home agents supply labor in the perfectly competitive domestic labor market, receive shares of profits from domestic firms, and pay lump-sum taxes. ${ }^{5}$

The domestic agent's optimization problem can, therefore be expressed as

$$
U_{t}=\sum_{s=t}^{\infty} \beta^{s-t}\left[\frac{\sigma}{\sigma-1} C_{s}^{\frac{\sigma-1}{\sigma}}+\chi \log \frac{M_{s}}{P_{s}}-\frac{k}{2} L_{s}^{2}\right]
$$

subject to the real budget constraint

$$
B_{t+1}+\frac{M_{t}}{P_{t}}=\left(1+r_{t}\right) B_{t}+\frac{M_{t-1}}{P_{t}}+\frac{W_{t}}{P_{t}} L_{t}-C_{t}-\tau_{t}+\frac{\pi_{t}}{P_{t}}
$$

where $\beta$ is the discount factor, $\sigma$ is the intertemporal elasticity of consumption and $\chi$ and $k$ are positive parameters. The only internationally traded bond is a riskless real bond denominated in

\footnotetext{
${ }^{4}$ Since the model is symmetric, we will only present the optimization problem of the domestic agent. The foreign agent optimization problem is analogous.

${ }^{5}$ We assume that domestic profits are uniformly distributed across domestic agents (see Hau, 2000, for a similar assumption).
} 
terms of the composite consumption good which we denote with $B ; r_{t}$ is the real interest rate on this bond between $t-1$ and $t$. $B$ also accounts for international shifts in wealth. $M_{t-1}$ denotes nominal money balances held at the beginning of period $t .{ }^{6}$ Agents also supply labor in a perfectly competitive labor market, receive profits shares from domestic firms $\frac{\Pi_{t}}{P_{t}}$, and pay lump-sum taxes $\tau_{t}$. C is a private consumption index and $\mathrm{P}$ the corresponding price index (both described more in detail below), while $\mathrm{W}$ denotes the nominal wage.

The first two arguments of the utility function are a real private consumption index (see equation (4)) and real money balances, while $L$ is total labor supply and the term $-\frac{k}{2} L_{s}{ }^{2}$ captures the negative effect on utility deriving from leisure loss. Equilibrium in the labor market implies

$$
L_{t}=L_{t}^{P}+L_{t}^{G}
$$

where $L_{t}^{P}$ and $L^{G}$ are the amount of labor demanded, respectively, by the domestic private and public sectors (see also Finn, 1998).

The private consumption index aggregates across the differentiated goods produced by all firms in the economy both at home and abroad. Firms enjoy a certain degree of monopolistic competition, specified by the magnitude of the parameter $\theta>1$. Denoting with $z$ a generic representative firm, with $c(z)$ the consumption of the differentiated output of this firm by the representative agent, and with $p(z)$ representing the domestic currency price of this output, the aggregate private consumption index and the corresponding price index take the following forms:

$$
\begin{gathered}
C=\left[\int_{0}^{1} c(z)^{\frac{\theta-1}{\theta}} d z\right]^{\frac{\theta}{\theta-1}}, \\
P=\left[\int_{0}^{1} p(z)^{(1-\theta)} d z\right]^{\frac{1}{1-\theta}} .
\end{gathered}
$$

We assume that the law of one price holds. This implies that the home and foreign consumer prices indexes are linked by the purchasing power parity (PPP) relationship $P=E P^{*}$, where $E$ is the nominal exchange rate, defined as the price of the foreign currency in terms of domestic currency.

Maximization of equation (1) subject to equation (2) yields the following first-order conditions:

\footnotetext{
${ }^{6}$ Note that we adopt Obstfeld and Rogoff (1996) timing convention, $M_{t}$ therefore denotes money between period $t$ and period $t+1$, while $B_{t}$ denotes bonds between period $t-1$ and $t$.
} 


$$
\begin{aligned}
& \frac{C_{t+1}}{C_{t}}=\left[\beta\left(1+r_{t+1}\right)\right]^{\sigma}, \\
& \frac{M_{t}}{P_{t}}=\chi C_{t}^{\frac{1}{\sigma}} \frac{1+i_{t+1}}{i_{t+1}}, \\
& C_{t}^{-\frac{1}{\sigma}} \frac{W_{t}}{P_{t}}=k L_{t},
\end{aligned}
$$

where $i_{t+1}$ is the nominal interest rate between $t$ and $t+1$. Equations (6) to (8) are, respectively, an Euler equation, a money demand equation, and a labor-leisure trade-off equation.

In order to keep our setup as simple as possible, while at the same time allowing a meaningful analysis of the effects of composition of fiscal policy, we assume that labor is the only factor of production used by firms, according to the simple production function

$$
Y_{t}=L_{t}^{P}
$$

We also assume that the labor supplied to the public sector is not used for productive purposes, but the public sector pays the same wage determined in the perfectly competitive domestic labor market. Furthermore, domestic agents are indifferent between working for the domestic government and working for domestic firms. This implies the following relationship between the price of a differentiated product and the nominal wage:

$$
p_{t}(z)=\frac{\theta}{\theta-1} W_{t}
$$

The real-term budget constraint faced by the government in each period is given by:

$$
\frac{W_{t}}{P_{t}} L_{t}^{G}+G_{t}=\tau_{t}+\frac{M_{t}-M_{t-1}}{P_{t}}
$$

Equation (11) expresses the fact that in every period the government can use lump-sum taxes and seignorage in order to finance public spending, both for non-wage government consumption and for government employment. Government consumption is defined as an aggregate across the differentiated goods $z$, with the same elasticity of substitution, and is therefore analogous to the private consumption aggregate defined in equation (4).

In the framework of this model the world demand for the representative differentiated product $z$ takes the form:

$$
Y(z)=\left[\frac{p(z)}{P}\right]^{-\theta}\left(C^{W}+G^{W}\right),
$$

where $C^{W}$ is world private consumption and $G^{W}$ is world public consumption. 


\section{A. The Initial Steady State}

We consider an initial steady state where government spending for goods and net foreign assets are zero for both countries, we accordingly denote this steady state with a zero subscript $\left(G_{0}=G_{0}^{*}=B_{0}=B_{0}^{*}=0\right)$. Notice that in our initial steady state government spending for employment is not necessarily zero. This will allow us to carry out a meaningful analysis of the macroeconomic effects of reductions in the size of public employment.

\section{B. Short-Run Nominal Rigidities}

We introduce short-run nominal rigidities in the form of one period preset prices in the currency of the producer, as in Obstfeld and Rogoff $(1995,1996)$, and Ganelli $(2003,2004)$. Domesticcurrency prices of domestic goods and foreign-currency prices of foreign goods are therefore rigid in the period in which the shock hits, but they are free to adjust to their new steady-state level in the period after the shock, when the economy reaches its new full-employment steady state. In terms of notation, in the log-linearized version of the model, we will denote short-run variables using tildes, and long-run variables using hats. Our assumption on short-run rigidity will imply that $\tilde{p}(h)=\widetilde{p}^{*}(f)=0$ in the log-linearized version of the model.

\section{Log-linearization}

Table 1 summarizes the log-linearization of the model around the initial steady state defined above. Given the symmetry of the model, only the domestic equations, the PPP equation, and the world goods market equilibrium equation are reported. Equations (13) to (24) are loglinearized versions of the price index, the Euler equation, the short-and long-run money demand equations, the labor-leisure supply equation, the equilibrium condition in the domestic labor market, the demand equation, the short-and long-run current account equations, the government budget constraint (excluding seignorage), the PPP, and the world goods market equilibrium condition. In Table $1, \frac{L_{0}^{P}}{L_{0}}$ and $\frac{L_{0}^{G}}{L_{0}}$ are, respectively, the initial share of labor used by the private and public sectors as shares of the total initial labor supply, and $H_{0}=\frac{W_{0} L_{0}^{G}}{P_{0} Y_{0}}$ is a measure of the initial public wage bill as a share of GDP. 
Table 1. The Log-linearized Domestic Economy

$\tilde{p}=n \tilde{p}(h)+(1-n)\left[e+\tilde{p}^{*}(f)\right]$
$\hat{c}=\tilde{c}+\sigma(1-\beta) \tilde{r}$
$\tilde{m}-\tilde{p}=\frac{1}{\sigma} \tilde{c}-\frac{\tilde{r}}{1+\delta}-\frac{\hat{p}-\tilde{p}}{\delta}$
$\hat{m}-\hat{p}=\frac{1}{\sigma} \hat{c}$
$\hat{l}=\tilde{p}(z)-\tilde{p}-\frac{1}{\sigma} \tilde{c}$
$\tilde{l}=\tilde{l}^{p} \frac{L_{0}^{P}}{L_{0}}+\tilde{l}^{g} \frac{L_{0}^{G}}{L_{0}}$
$\tilde{l}^{p}=\tilde{y}=\theta[\tilde{p}-\tilde{p}(h)]+\tilde{c}^{W}+\tilde{g}^{W}$
$\hat{b}=\tilde{y}-\tilde{c}-(1-n) \tilde{e}-\tilde{g}$
$\hat{c}=\delta \hat{b}+\hat{y}+\hat{p}(h)-\hat{p}-\hat{g}$
$H_{0}\left(\tilde{w}+\tilde{l}^{G}\right)+\tilde{g}=\tilde{\tau}$
$\tilde{e}=\tilde{p}-\tilde{p}^{*}$
$\tilde{l}^{p, W}=\tilde{y}^{W}=\tilde{c}^{W}+\tilde{g}^{W}$

Source: Author's calculations.

\section{The EFFECTS OF GovernMent SPENDING COMPOSITION}

In this section we will look at the international macroeconomic effects of two different policies. Under one policy, the domestic government asymmetrically reduces the amount of spending for public employment, matching this reduction with a reduction in taxes. Under the second policy, the domestic government changes the composition of its spending, by reducing public employment and using this reduction to finance an increase of spending on non-wage public consumption. During our analysis we keep monetary policy constant and we, therefore, abstract from seignorage.

\section{A. Graphical Solution}

In order to study the effects of the policy that we want to analyze, it is useful to combine the various equations in order to obtain two basic relationships, which can be used to provide a simple and intuitive graphical solution of the model.

Combining the PPP equation, the Euler equation, the money demand equation, and their foreign counterparts, it is possible to derive the following relationship between short-run relative private consumption and the exchange rate: 


$$
\tilde{e}=-\frac{1}{\sigma}\left(\tilde{c}-\tilde{c}^{*}\right)
$$

Equation (25) is standard in a framework in which money demand depends on consumption. It expresses the fact that an increase in domestic consumption relative to foreign, by increasing money demand for a given level of the money supply, requires an appreciation of the domestic currency (a decrease in $\tilde{e}$ ) in order to restore equilibrium in the money market. In Ganelli (2004), this mechanism is referred to as the "money demand" effect.

A second relationship between the exchange rate and relative consumption can be derived by combining the other equations of the model. In particular, combining the domestic and foreign long-run demand equations and current account equations, and assuming symmetric initial shares of labor in the private and public sectors between the two countries $\left(\frac{L_{0}^{P}}{L_{0}}=\frac{L_{0}^{P^{*}}}{L_{0}^{*}}\right.$ and $\left.\frac{L_{0}^{G}}{L_{0}^{P}}=\frac{L_{0}^{G^{*}}}{L_{0}^{P^{*}}}\right)$ we can derive the following equation:

$$
\hat{c}-\hat{c}^{*}=\frac{\delta}{1-n} \hat{b}+\frac{\theta-1}{\theta}\left[\frac{L_{0}}{L_{0}^{P}}\left(\hat{l}-\hat{l}^{*}\right)+\frac{L_{0}^{G}}{L_{0}^{P}}\left(\hat{l}^{g}-\hat{l}^{g^{*}}\right)\right]-\left(\hat{g}-\hat{g}^{*}\right)
$$

Making use of the domestic and foreign labor-leisure equations we can derive

$$
\hat{l}-\hat{l}^{*}=-\frac{L_{0}^{G}}{\theta L_{0}^{P}+L_{0}}\left(\hat{l}^{g}-\hat{l}^{g^{*}}\right)-\frac{1}{\sigma} \frac{\theta L_{0}^{P}}{\theta L_{0}^{P}+L_{0}}\left(\hat{c}-\hat{c}^{*}\right)
$$

Combining equation (26) and equation (27), we can derive an expression for long-run net foreign assets as follows:

$$
\hat{b}=\frac{1-n}{\delta} K\left(\hat{c}-\hat{c}^{*}\right)+\frac{1-n}{\delta} \frac{\theta-1}{\theta} \frac{L_{0}}{L_{0}^{P}} \frac{L_{0}^{G}}{\left(\theta L_{0}^{P}+L_{0}\right)}\left(\hat{l}^{g}-\hat{l}^{g^{*}}\right)+\frac{1-n}{\delta}\left(\hat{g}-\hat{g}^{*}\right)
$$

where $K=\frac{\sigma\left(\theta L_{0}^{P}+L_{0}\right)+(\theta-1) L_{0}}{\theta L_{0}^{P}+L_{0}}$ is a positive constant, which depends on the degree of monopolistic distortion in the economy, on the intertemporal rate of substitution of consumption, and on the share of labor in the private sector at the initial steady state. ${ }^{7}$

In order to eliminate $\hat{b}$ we can make use of the short-run current account equations. Subtracting from equation (20) its foreign counterpart and making use of the fact that the hypothesis of one period price stickiness and the domestic and foreign demand equations imply $\tilde{y}^{P}-\tilde{y}^{P^{*}}=\theta \tilde{e}$, we get:

\footnotetext{
${ }^{7}$ In order to prove that $K$ is positive, it is enough to remember that $\theta>1$ by definition.
} 


$$
\hat{b}=(1-n)\left[(\theta-1) \tilde{e}-\left(\tilde{g}-\tilde{g}^{*}\right)-\left(\tilde{c}-\tilde{c}^{*}\right)\right]
$$

Using equation (14) and its foreign counterpart, it can be easily shown that in this framework relative consumption follows a unit root process (i.e., $\hat{c}-\hat{c}^{*}=\tilde{c}-\tilde{c}^{*}$ ). ${ }^{8}$ Combining equation (28) with equation (29), and making use of the "unit root" result, we can eliminate $\hat{b}$ and obtain a second relationship between sort-run consumption and exchange rate:

$$
\begin{aligned}
\tilde{e}= & \frac{1}{\theta-1}\left(1+\frac{K}{\delta}\right)\left(\tilde{c}-\tilde{c}^{*}\right)+\frac{1}{\delta} \frac{\theta-1}{\theta} \frac{L_{0}}{L_{0}^{P}} \frac{L_{0}^{G}}{\left(\theta L_{0}^{P}+L_{0}\right)}\left(\hat{l}^{g}-\hat{l}^{g^{*}}\right)+\frac{1}{\theta-1}\left(\tilde{g}-\tilde{g}^{*}\right) \\
& +\frac{1}{\delta(\theta-1)}\left(\hat{g}-\hat{g}^{*}\right) .
\end{aligned}
$$

Unlike equation (25), equation (30) also depends on some policy variables such as government employment and non-wage government consumption. Since $K$ is a positive constant, equation (30) expresses a positive relationship between $\tilde{e}$ and $\tilde{c}-\tilde{c}^{*}$. Equation (30) describes another mechanism at work in the model, which goes in the opposite direction compared to the "money demand" effect. For a given government policy stance, an increase in domestic consumption relative to foreign worsens the current account of the domestic country, thus creating a pressure for depreciation of the domestic currency (an increase in $\tilde{e}$ ).

Figure 1 provides a graphical representation of equations (25) and (30) for given government policies (i.e., assuming no shocks to government employment and non-wage consumption in both countries: $\hat{l}^{G}=\hat{l}^{G^{*}}=\tilde{g}=\tilde{g}^{*}=\hat{g}=\hat{g}^{*}=0$ ). The intuition for the upward sloping shape of equation (30) is the "current account" effect, which we have just described, while the "money demand" effect explains the downward slope of equation (25). This graphical apparatus can be usefully employed in order to analyze the macroeconomic effects of policy changes.

\footnotetext{
${ }^{8}$ This is a well-known result in this framework (see Obstfeld and Rogoff, 1996).
} 
Figure 1. The Two Equilibrium Relationships

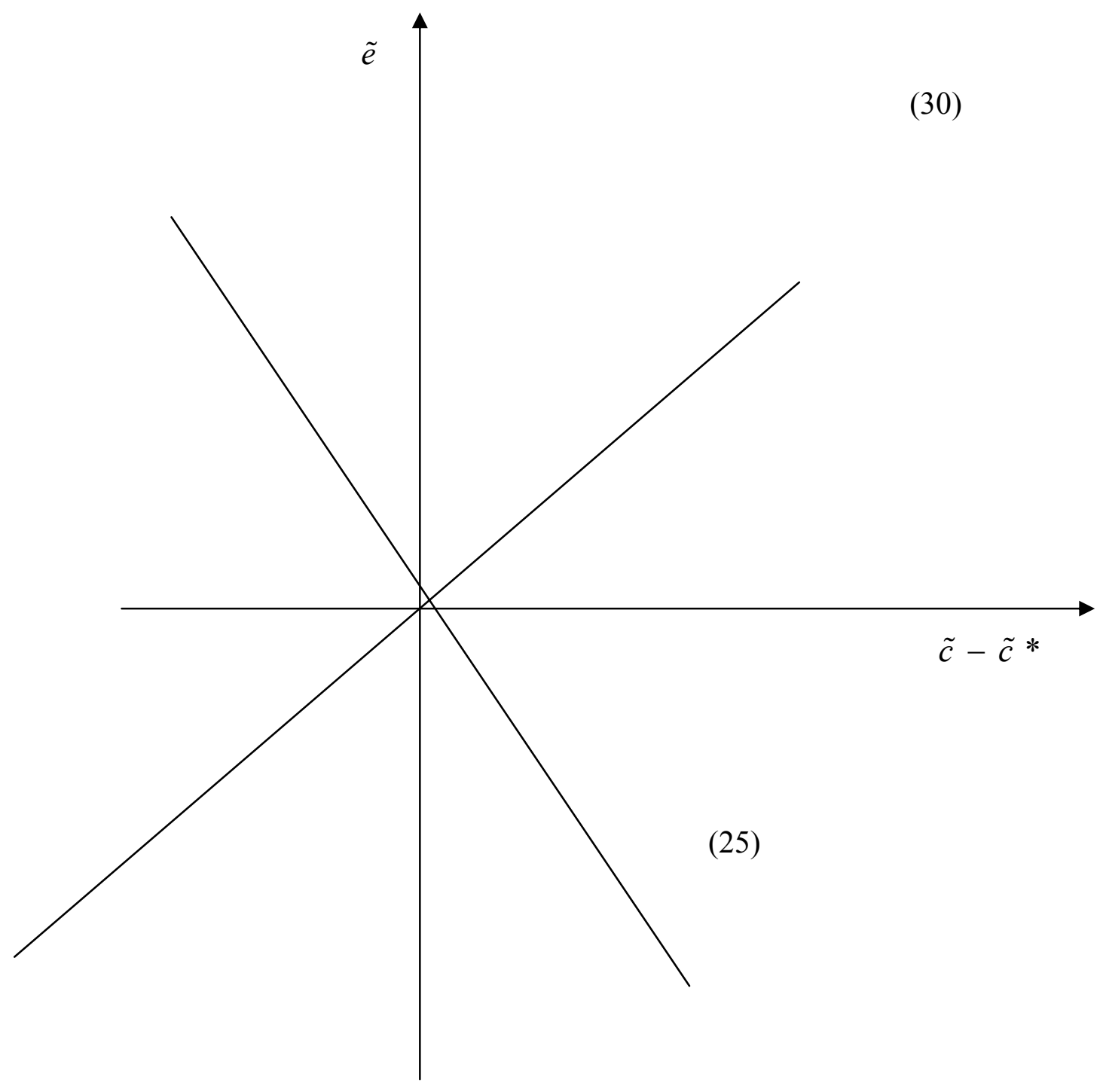

Source: Author's calculations. 


\section{B. Effects of a Reduction in Government Employment}

Figure 2 illustrates the effects of a reduction in domestic government employment compared to foreign. Since equation (25) is not influenced by changes in government policies, the downward sloping curve is the same as in Figure 1.

Figure 2. Effects of a Reduction in Domestic Government Employment

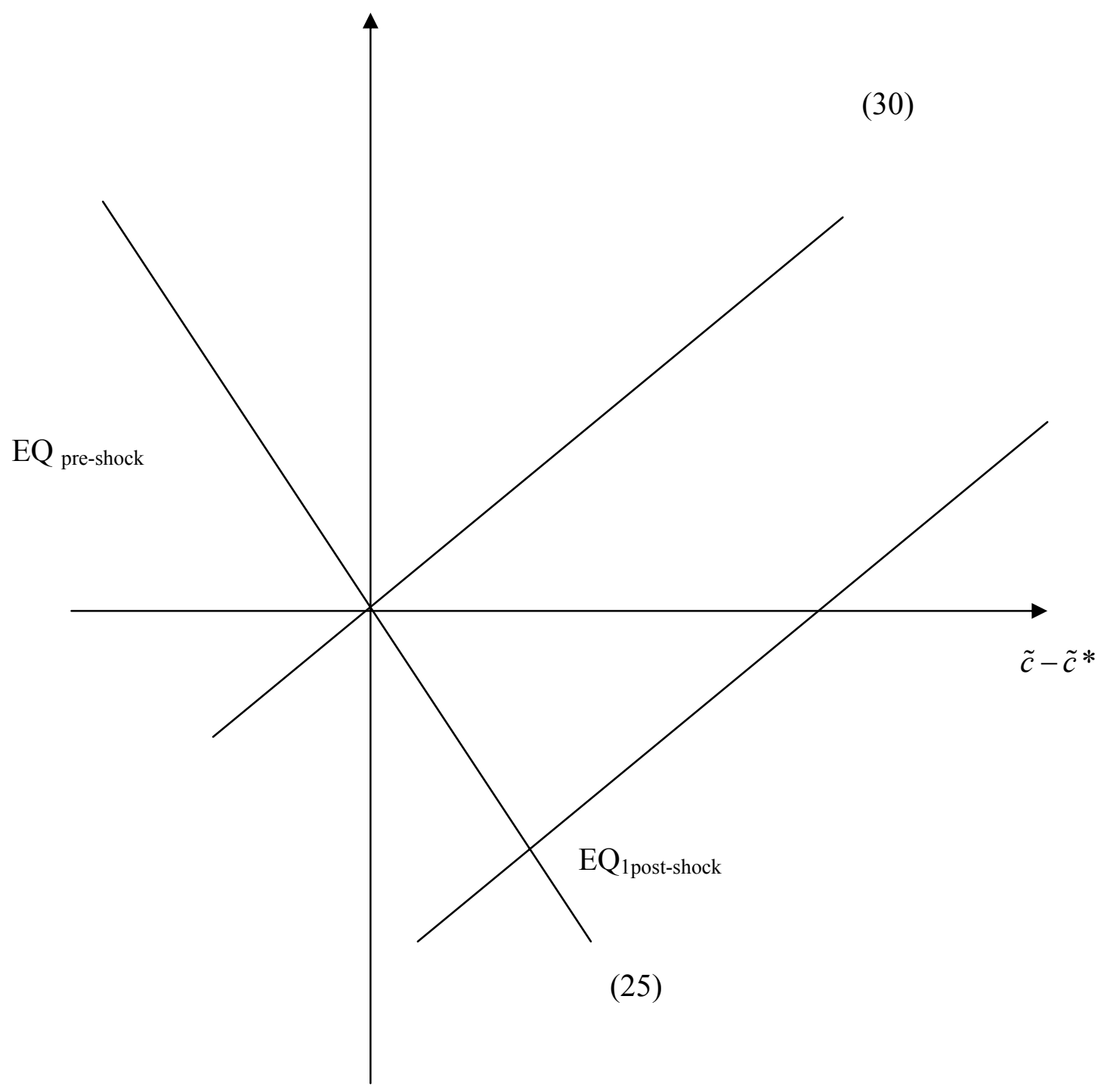

Source: Author's calculations. 
An analysis of equation (30), on the other hand, shows that, for given non-wage government consumption $\left(\tilde{g}=\widetilde{g}^{*}=\hat{g}=\hat{g}^{*}=0\right)$, an asymmetric decrease in domestic government employment relative to foreign $\left(\hat{l}^{G}-\hat{l}^{G^{*}}<0\right)$ will imply a lower level of $\tilde{e}$ (a domestic appreciation) for any given $\left(\tilde{c}-\tilde{c}^{*}\right)$. In graphical terms, such policy shifts equation (30) rightward (Figure 2). The new equilibrium, therefore, implies a higher level of relative private consumption and a more appreciated exchange rate. ${ }^{9}$

An intuition for the result that lowering government spending on employment implies an increase in domestic consumption relative to foreign, can be found in the fact that this policy reduces the amount of private resources used by the government. A sectoral reallocation of labor involving a shift out of the public and into the private sector takes place. This implies a reduction of the tax burden on the economy, thus increasing the total amount of private wealth available in the domestic economy, and allowing domestic agents to consume more compared to foreigner.

It is important to notice that it is the "future" component of the policy that impacts consumption decisions. In other words, if the reduction in public employment was only temporary $\left(\tilde{l}-\tilde{l}^{*}<0\right.$ with $\hat{l}=\hat{l}^{*}=0$ ), there would be no consumption reallocation. This is because in the short run, due to the nominal rigidity, the reduced demand for labor in the public sector would not be compensated by an increased demand in the private sector. The aggregate consumption behavior of the economy would not be affected in that case, because the gain associated with the reduction in the tax burden would be offset by the loss of labor income stemming from public sector retrenchment.

If the reduction in government employment is permanent, on the other hand, agents anticipate that they will be able to benefit from lower taxes even in the long run, when the economy will be in a full employment equilibrium. Furthermore, in the long run the reduction in the tax burden will not be offset by lower income, because the reduced public employment will be compensated by an increase in employment in the private sector. Due to the presence of rational expectations, domestic agents anticipate the lifetime increase in wealth and raise consumption immediately.

The "money demand" effect, which we have described above, implies that an appreciation of the domestic exchange rate is necessary in order to reestablish equilibrium in the money market. This is due to the fact that the increase in relative consumption increases domestic money demand relative to foreign for a given monetary policy stance. Additionally, under our assumptions (see equation (9)), the sectoral shift in employment from the public to the private sector implies a more productive use of labor, therefore increasing the total amount of resources

\footnotetext{
${ }^{9}$ This can also be shown by substituting equation (25) directly into equation (30) and noticing that this implies a negative relationship between $\tilde{c}-\tilde{c}^{*}$ and $\hat{l}-\hat{l}^{g^{*}}$.
} 
available in the domestic economy and reducing the impact of the "current account" effect. This contributes to explain why the "money demand" effect dominates the "current account" effect in determining the short-run impact on the exchange rate.

Since we know that $\tilde{y}-\tilde{y}^{*}=\tilde{\theta e}$, we can conclude that the appreciation of the exchange rate also implies a decrease in domestic output compared to foreign. This is due to the expenditure switching effect related to the appreciation of the domestic currency, which shifts demand from domestic goods to foreign ones.

\section{Long-Run Effects}

In order to assess the long-run effects of a domestic reduction in public employment, we can start by noticing that the "unit root" result $\left(\hat{c}-\hat{c}^{*}=\tilde{c}-\tilde{c}^{*}\right)$ implies that the effect of the policy change on relative consumption in the long run will be the same as in the short run. A reduction in domestic public employment, therefore, implies an increase in domestic consumption relative to foreign both in the short and in the long run.

In order to better understand the long-run implications of the policy that we are considering, it is also useful to derive its effects on the long-run net foreign assets position of the domestic country $\hat{b}$. A possible method to solve for $\hat{b}$ is to combine equation (25) and equation (30) in order to express $\tilde{c}-\tilde{c}^{*}$ as a function of policy variables only. The next step is to use the "unit root" result $\left(\hat{c}-\hat{c}^{*}=\tilde{c}-\tilde{c}^{*}\right)$ in order to find an expression which can be used to eliminate $\hat{c}-\hat{c}^{*}$ in equation (28), yielding the following reduced form for $\hat{b}$

$$
\begin{aligned}
& \hat{b}=\frac{1-n}{\delta} \frac{\theta-1}{\theta} \frac{L_{0}}{L_{0}^{P}} \frac{L_{0}^{G}}{\left(\theta L_{0}^{P}+L_{0}\right)}\left(\frac{K}{K_{2}}+1\right)\left(\hat{l}^{g}-\hat{l}^{g^{*}}\right)+ \\
& +\frac{1-n}{\delta} \frac{K}{K_{2}} \frac{1}{\theta-1}\left(\tilde{g}-\tilde{g}^{*}\right)+\frac{1-n}{\delta}\left(\frac{K}{K_{2}} \frac{1}{\delta(\theta-1)}+1\right)\left(\hat{g}-\hat{g}^{*}\right)
\end{aligned}
$$

where $K_{2}=\frac{1}{\sigma}+\frac{1}{\theta-1}\left(1+\frac{K}{\delta}\right)>0$.

From equation (31) it is clear that a reduction in domestic government employment has a negative effect on the net foreign asset position of the domestic country. The intuition for this result is related to the increase in relative consumption both in the short and in the long run which, together with the short-run reduction in relative output, create pressures for a worsening of the long-run financial position relative to the foreign country.

In order to have some insights on the impact on long-run output, it is possible to combine the demand function (19), the long-run current account function (21), and their foreign counterparts, this yields (omitting for simplicity terms independent of changes in government employment): 


$$
\hat{y}-\hat{y}^{*}=-\left(\frac{\theta}{\theta-1}\right) \frac{\delta}{1-n} \hat{b}+\frac{\theta}{\theta-1}\left(\hat{c}-\hat{c}^{*}\right)
$$

Equation (32) illustrates the main economic channels that impact relative output in the long run. The negative relationship between $\hat{b}$ and $\hat{y}-\hat{y}^{*}$ illustrate the fact that higher net foreign assets would make domestic agents richer, therefore prompting them to consume more leisure and work less. On the other hand, the positive relationship between relative consumption and relative output illustrate the need to work more in order to finance higher goods consumption. Since we have already shown that a reduction in public employment implies a reduction in $\hat{b}$ and an increase in $\left(\hat{c}-\hat{c}^{*}\right)$, it is clear from equation (32) that the output of the domestic country relative to foreign will increase in the long run following a reduction in public employment.

Taking into account the simple relationship that we have postulated between labor input and production in the private sector, it is straightforward to verify that the formal results on the output dynamics confirm our intuitive explanation on the sectoral shift from public to private employment, which implies an increase of private employment in the long run.

We believe that this paper is the first contribution in the "new open economy macroeconomics" framework to differentiate between government spending for public employment and for nonwage public consumption. As already stressed in the introduction, however, this problem was analyzed in the RBC tradition by Finn (1998). Our contribution differs from Finn's in at least three aspects. First, since in our setup we incorporate some typically Keynesian features, such as imperfect competition and nominal rigidities, we can carry out an analysis that differentiates the effects of changes in public employment between the period in which the economy is characterized by underutilization of resources (the short run) and the full employment period (the long run). In comparing our results with Finn's, it is important to bear in mind that she considers an expansion in public employment as the benchmark exercise (Finn, 1998, p. 642), while we have focused on the effect of public employment retrenchment.

Our analysis shows that the result regarding the effects of changes in government employment on private consumption identified by Finn is likely to be broadly consistent with the one that we find. Regarding output dynamics, however, our analysis implies that a fall in output is not always the necessary outcome of an increase in government employment, contrary to what Finn finds. In our model, if government employment were increased, the output of the domestic country would increase compared to the foreign in the short run. Admittedly, the country competitiveness factor would play a role in this result as would the effects of initial underutilization of resources.

This brings us to the second important difference between our model and Finn's, namely our open economy focus, which allows us to look at the effects of changes in public employment on variables like the exchange rate and the external position of the country. 
Finally, we solve our model by deriving analytical solutions and using a simple graphical apparatus, rather than using numerical simulations. Although this prevents us from carrying out a quantitative analysis of the impact of the various components of public spending on the cycle, which is an extremely interesting feature of Finn's paper, we also believe that our method presents some advantages. In particular, the simple graphical apparatus that we present is helpful in providing an intuitive explanation for the results. Deriving analytical solutions also allows us to study the effects of a change in the composition of government spending (an increase in government consumption financed by public employment retrenchment). We now turn to the analysis of such a policy.

\section{Effects of a Shift in Government Spending Composition}

In Section III C we focused on the consequences of a domestic reduction in public employment for constant non-wage government consumption. As we have already stressed, when such policy is implemented, domestic agents benefit from a reduction in taxes. In this section we analyze the effects of a slightly different policy, in which the reduction in government employment is used to finance an increase in non-wage government consumption.

From the log-linearized version of the government budget constraint equation (and from its foreign equivalent) it follows that the following relationship holds:

$$
\bar{g}-\bar{g}^{*}=-H_{0}\left(\bar{l}^{G}-\bar{l}^{G^{*}}\right)
$$

where the bar superscript denotes permanent policies (i.e., $\bar{g}=\widetilde{g}=\hat{g}$,etc.).

This implies that equation (30) can be rewritten as follows

$$
\tilde{e}=\frac{1}{\theta-1}\left(1+\frac{K}{\delta}\right)\left(\tilde{c}-\tilde{c}^{*}\right)+\left[\frac{1}{\delta} \frac{\theta-1}{\theta} \frac{L_{0}}{L_{0}^{P}} \frac{L_{0}^{G}}{\left(\theta L_{0}^{P}+L_{0}\right)}-\frac{1}{\theta-1}\left(\frac{1+\delta}{\delta}\right) H_{0}\right]\left(\hat{l}^{g}-\hat{l}^{g^{*}}\right)
$$

where the impact of the policy that we are considering will be captured by the expression in the square bracket. Since, as in the case of the previous policy, equation (25) will still be independent of government policies, equation (34) will determine the impact on short-run relative consumption and exchange rate. Since the expression is the sum of a positive and of a negative term, it is clear that a reduction in public employment, which is used to finance an increase in non-wage public consumption, will have an ambiguous effect on the various macroeconomic variables. If the positive term in the square bracket is dominant, equation (34) implies that, following the reduction in public employment, the same level of relative consumption will be consistent with a lower exchange rate (equation (34) will shift rightward, as equation (30) does in Figure 2), while the opposite (leftward shift) will be true if the negative term dominates.

The intuition for the ambiguous result can be found by noticing that when the reduction in public employment is used to finance an increase in government spending, agents do not benefit from the reduction in the tax burden. Since the reduction in labor is only absorbed by the private 
sector in the long run, this policy, therefore, implies a net loss of labor income for domestic agents, which should depress domestic consumption compared to foreign consumption. At the same time, however, the increased government consumption stimulates demand, therefore increasing profits and contributing to increasing private wealth, which has a positive effect on private wealth and therefore on consumption.

Inspection of the expression in square bracket in equation (34), suggests that the case of a leftward shift of the curve is more likely the bigger the share of public wage bill on GDP at the initial equilibrium, $H_{0}$. This is consistent with our intuitive explanation for the ambiguous effect of such a policy, since a situation in which a larger initial share of income is derived from employment in the public sector will imply a stronger negative wealth effect, and therefore, a stronger pressure for reduction in consumption, when public employment retrenchment happens.

\section{Conclusions}

In this paper we introduced a distinction between government spending for public employment and for non-wage public consumption in a "new open economy macroeconomics" model. This allowed us to help overcome a paradox of economic literature, noted by Alesina and Perotti (1995), which implies that the academic debate on the macroeconomic effects of fiscal policy refers almost exclusively to the impact of government consumption. Since the "new open economy macroeconomics" framework is emerging as the new paradigm for the analysis of macroeconomic interdependence, our contribution offers some insights on the effects of public spending composition in this new framework. We have shown that a reduction in domestic employment used to reduce the tax burden implies both, an immediate increase in domestic consumption compared with foreign consumption, and an appreciation of the domestic exchange rate. When the reduction in public employment is used to finance an increase in domestic non-wage government consumption, the results are ambiguous and can be affected by the initial share of private income derived from employment in the public sector.

The research presented in this paper could be extended in various directions. In particular, introducing government investment into the model would allow analysis of a wider range of policies. Since in the framework presented in this paper Ricardian equivalence holds and government debt would not have real effects, we have limited our analysis to reductions in government employment matched by changes either in consumption spending or in taxation. Extending the model to a framework in which government debt can have real effects (e.g., along the lines of Ganelli, 2004) would allow an analysis of how the composition of government spending interacts with various financing alternatives. 


\section{REFERENCES}

Alesina, Alberto, and Roberto Perotti, 1995, "Fiscal Expansions and Adjustments in OECD Countries," Economic Policy, pp. 207-48.

Finn, Mary G., 1998, "Cyclical Effects of Government Employment and Goods Purchases," International Economic Review, Vol. 39, pp. 635-57.

Ganelli, Giovanni, 2003, "Useful Government Spending, Direct Crowding-Out and Fiscal Policy Interdependence," Journal of International Money and Finance, Vol. 22 (1), pp. 87-103.

, 2004, "The New Open Economy Macroeconomics of Government Debt," forthcoming in the Journal of International Economics.

Hau, Harald, 2000, "Exchange Rate Determination: the Role of Factor Price Rigidities and Nontradeables," Journal of International Economics, Vol. 50 (2), pp. 421-47.

Lane, Philip R., 2001, “The New Open Economy Macroeconomics: A Survey,” Journal of International Economics, Vol. 54 (2), pp. 235-66. , and Giovanni Ganelli, 2003, "Dynamic General Equilibrium Analysis: The Open Economy Dimension," Elements in Dynamic Macroeconomic Analysis, ed. by S. Altug, J. Chadha, Lane Phillip, and C. Nolan (Cambridge: Cambridge University Press). , and Roberto Perotti, 2003, "The Importance of Composition of Fiscal Policy: Evidence from Different Exchange Rate Regimes," Journal of Public Economics, Vol. 87, pp. 2253-79.

Obstfeld, Maurice, and Kenneth Rogoff, 1996, "Foundations of International Macroeconomics," Chapter 10, Cambridge, Massachusetts: MIT Press. , and Kenneth Rogoff, 1995 "Exchange Rate Dynamics Redux," Journal of Political Economy, Vol. 103, pp. 624-60. 